Int. J. Dev. Biol. 56: 463-472 (2012)

doi: $10.1387 / \mathrm{ijdb} .123498 \mathrm{hs}$

\title{
Transplantation analysis of developmental mechanisms in Hydra
}

\author{
HIROSHI SHIMIZU* \\ National Institute of Genetics, Yata, Mishima, Shizuoka, Japan
}

\begin{abstract}
Since the pioneering work of Ethel Browne (1909) who demonstrated for the first time the concept of organizer activity, i.e. the potency of an apical Hydra tissue to induce a secondary axis when transplanted onto a host, Hydra flourished as a fruitful model system for developmental studies. Over the next 60 years this efficient transplantation approach identified graded biological activities along the body column of $H y d r a$ named HeadActivation and Head Inhibition. These properties inspired theoretical modelers including LewisWolpert, Alfred Gierer and Hans Meinhardt to propose models for morphogenesis, respectively the positional information (1969) and reaction-diffusion (1972) models. In 1973, Tsutomu Sugiyama and Toshitaka Fujisawa initiated in Mishima a unique project to analyze the properties of $\mathbf{H y d r a}$ strains with distinct morphological and developmental characters. To this end, they collected in several areas of Japan multiple Hydra strains that they subsequently characterized and crossed. They also established a lateral transplantation strategy that was much more powerful than the previous ones, as it combined quantitative measurements with cellular analyses thanks to the chimera procedures developed by Campbell and colleagues. Indeed this approach provided a paradigm to quantify in any morphological phenotype the Head Activation and Head Inhibition levels along the body column. In this article, I review the various strains identified by Sugiyama and colleagues, the principles and the main results deduced from the quantitative lateral transplantation strategy. In addition, I briefly discuss the relevance of this approach in the era of molecular biology.
\end{abstract}

KEY WORDS: Hydra, regeneration, transplantation, inhibition, positional information, gradient

\section{Introduction}

Today genetic analyses are popular in many model organisms, however in the 1970s when Sugiyama and Fujisawa initiated a project to investigate the basic mechanism of pattern formation in Hydra at National Institute of Genetics at Mishima, genetic analyses were restricted to a limited number of organisms. Hydra is a freshwater cnidarian polyp with a simple anatomy that is shown and described in details in this issue in several places (e.g. Boettger and Hassel, 2012; Bossert and Galliot, 2012; Martinez and Bridge, 2012). As a specific trait, adult Hydra undergoes both sexual and asexual reproduction (budding). When well fed, it proliferates primarily by budding, as observed both in the lab and in the wild, whereas sexual reproduction is a relatively infrequent event (see in this issue the reviews by Boettger and Hassel, and by Nishimiya-Fujisawa). It is assumed that over a number of generations asexual reproduction could lead to the accumulation of mutations in the germ cells, which would yield phenotypes in the progeny resulting from sexual reproduction. If true, the hatching and survival rates of fertilized eggs might be relatively low due to a significant load of deleterious recessive mutations.

When Sugiyama and Fujisawa initiated genetic studies, several authors had already described the complete life cycle of Hydra, showing that it extends over several months as it takes weeks to months for fertilized eggs to hatch (McConnell, 1938; Moore and Campbell, 1973). In addition, Moore and Campbell (1973) found that the hatching rate and the survival rate of hatchlings were both very low. Altogether these data indicated that forward genetic screens following application of mutagens were not easily feasible in Hydra.

In place of forward genetic screening, Sugiyama and Fuji-

Abbreviations used in this paper: HA, head activation; HI, head inhibition; Hm, Hydra magnipapillata.

\footnotetext{
*Address correspondence to: Hiroshi Shimizu. National Institute of Genetics, 1,111 Yata, Mishima 411-8540. Shizuoka, Japan. Tel: +81-559-816764.

Fax: +81-559-816768. e-mail: hshimizu@nig.ac.jp
}

Final, author-corrected PDF published online: 5 June 2012

ISSN: Online 1696-3547, Print 0214-6282

(C) 2012 UBC Press

Printed in Spain 
TABLE 1

\section{DIFFERENT STRAINS COLLECTED OR PRODUCED BY S. FUJISAWA (1979) WITH SOME MODIFICATIONS}

\begin{tabular}{|c|c|c|c|c|c|}
\hline $\begin{array}{l}\text { Hydra magnipapillata } \\
(\mathrm{Hm}) \text { strains }\end{array}$ & Anatomy \& Physiology & Developmental characters & Cellular characters & Origin & Reference \\
\hline Hm-104 (male) & normal & & & wild & (Sugiyama and Fujisawa, 1977a) \\
\hline $\mathrm{Hm}-105$ (male) & & & & wild & (Sugiyama and Fujisawa, 1977a) \\
\hline Hm-107 (female) & & & & wild & (Sugiyama and Fujisawa, 1977a) \\
\hline Hm-117 (female) & & & & wild & (Sugiyama and Fujisawa, 1977a) \\
\hline Hm L1 & & & & wild & (Sugiyama and Fujisawa, 1977a) \\
\hline Hm L2 (male) & & & & wild & \\
\hline Hm L4 (female) & Large size & Low budding rate & & wild & (Takano and Sugiyama, 1983) \\
\hline Hm SSE (male) & & & & wild & (Sugiyama and Sugimoto, 1985) \\
\hline Hm SSC (female) & & & & Wild & (Sugiyama and Sugimoto, 1985) \\
\hline Hm mh-1 & multiheaded & & & $(\mathrm{F} 1)$ & (Sugiyama, 1982) \\
\hline Hm reg-16 & & Head regeneration-deficient & & $(\mathrm{F} 2)$ & $\begin{array}{l}\text { (Sugiyama and Fujisawa, 1977b; } \\
\text { Achermann and Sugiyama, 1985) }\end{array}$ \\
\hline Hm reg-19 & & Head regeneration-deficient & & $(\mathrm{F} 2)$ & (Sugiyama and Fujisawa, 1977a) \\
\hline Hm nem-3 & & & nematocyst (holotrichous isorhiza) deficient & (F1) & (Sugiyama and Fujisawa, 1977a) \\
\hline Hm nem-4 & & & nematocyst (stenotele) deficient & $(\mathrm{F} 2)$ & (Sugiyama and Fujisawa, 1978b) \\
\hline Hm maxi-1 & Large size & & & $(\mathrm{F} 1)$ & (Sugiyama and Fujisawa, 1977a) \\
\hline Hm mini-4 & Small size & & & (F1) & (Sugiyama and Fujisawa, 1977a) \\
\hline Hm sf-1 & Heat-shock sensitive & & produces interstitial cell-deficient strain upon heat-shock (nf-1) & (F5) & (Sugiyama and Fujisawa, 1978a) \\
\hline Hm sf-21 & & & produces interstitial cell-deficient strain (nf-21) & $(\mathrm{F} 1)$ & (Sugiyama and Fujisawa, 1979) \\
\hline Hm nf-17 & Food ingestion deficient & & & (F1) & (Sugiyama and Fujisawa, 1978a) \\
\hline
\end{tabular}

The main characteristics of each strain are indicated, for details refer to the original description. SexCr: sexual-cross.

sawa collected Hydra from various locations in Japan and let them undergo sexual reproduction in the laboratory to produce $\mathrm{F} 1$ and F2 progeny, with the expectation that the F2 generation would reveal recessive mutations present in the parental lines. Such offspring were termed "mutants" although the presence of a genetic mutation had not been rigorously demonstrated in any of them. From the strains obtained at the F1 to F6 generations, plus some chimeric strains constructed from some of these strains, they carried out systematic lateral transplantation analyses as initially described by Browne (1909) and later by Yao (1945), Webster and Wolpert (1966). In this article, I will mainly review the information that was obtained by Sugiyama and colleagues from these studies while referring to methodological contribution by Campbell and colleagues.

\section{Strategy for analyzing head-forming mechanisms in Hydra}

Production of a variety of Hydra strains through inbreeding

Once collected from the field the animals were maintained in the laboratory as described by Loomis and Lenhoff (1956), i.e. fed with brine shrimp nauplii and maintained at $18^{\circ} \mathrm{C}$ in fresh hydra medium modified according to Sugiyama and Fujisawa (1977b). Formation of eggs and testis was induced by altering the culture conditions, which depending on the strains might consist of aerating the culture medium to make it acidic, feeding animals poorly, shifting the temperature either to a higher or lower range, etc... Hydra strains are generally dioecious, i.e. either male or female, only occasionally hermaphrodites, the same polyp carrying both eggs and testis. To obtain fertilized eggs, male and female polyps of two different strains were kept in the same beaker for a week or two. As mentioned above, Sugiyama and Fujisawa conventionally called those strains obtained by cross-breeding "mutants", which, however, does not imply genetic mutation. In this review to avoid any confusion, we will simply call them here by name of the strains. A wild type strain of Hydra magnipapillata $(\mathrm{Hm})$ that was collected in a pond in the neighborhood of National Institute of Genetics in Mishima, named strain 105 was used as the standard strain. The anatomical, developmental and cellular characters of these strains are listed in Table 1 as initially reported by Sugiyama and Fujisawa in 1979.

\section{The lateral transplantation procedure}

To take advantage of the different characters that were recorded on these strains, e.g. polyp size, polyp shape, head regenerative capacity etc., Sugiyama established experimental strategies aiming at measuring the morphogenetic properties of each of them. For this purpose they applied the lateral transplantation procedure that had led Lewis Wolpert several years earlier to propose the positional information theory (Wolpert, 1969; Wolpert et al., 1971; Wolpert et al., 1974). A critical issue in the regeneration phenomenon is how the cells at the regenerating site know that they are in charge of forming the missing organ. The positional information theory provided a very simple mechanism for it by setting up gradients of morphogenetic substances (morphogens) that are maintained by diffusion from the source at one end to the sink at the other end. According to this theory, cells obtain information about their position by the level of the morphogens to which they are exposed. As an example, the strain with a large polyp size, is expected to have a slower diffusion of morphogens and as a result a longer diffusion distance. This longer diffusion distance naturally stretches the distance between the source and the sink, which is reflected by the larger size of the animal.

Regeneration of any missing part occurs with high fidelity in Hydra. If one removes both head and foot from a polyp leaving cylindrical body column tissue, head regenerates at the apical end and foot regenerates at the basal end. This is also true for small pieces of tissue that are used in the lateral transplanta- 
tion experiments (Shimizu et al., 1993). When a piece of tissue excised from the donor polyp is immediately inserted into a slit made on the body of an intact host polyp, occasionally head-like structures consisting of one or more tentacles with or without hypostome is formed on the transplanted tissue within several days (Browne, 1909; Yao, 1945; Webster and Wolpert, 1966). Whether this ectopic head structure forms or not depends firstly on the original position of the donor tissue and secondly on the position where the donor tissue is inserted on the host polyp.

Sugiyama and colleagues carried out lateral transplantation experiments following the basic principles established by their predecessors (Fig. 1; see also Browne, 1909; Yao, 1945; Webster and Wolpert, 1966) but in a more sophisticated manner. First, they used animals cropped from a rigorously controlled mass culture as newly dropped polyps, fed daily for 3-4 days, and having the first bud protrusion when used (Takano and Sugiyama, 1983). Second, they labeled the donor tissue with Evans Blue, which made it easy to check whether the donor tissue stays at the site and the transplantation was successful. This was important because it occurred in some cases that the transplanted donor tissue was either sloughed off or swallowed into the gut through the slit resulting in the failure of head formation. Such failure may accidentally be recorded as no head formation although the transplantation was successful. Third, they strictly monitored the positional origin of the donor tissue and the position of tissue insertion on the host (Takano and Sugiyama, 1984).

\section{Defining the head-forming properties in Hydra}

\section{Assessment of the head activation (HA) levels upon lateral transplantation}

The concepts of head activation $(\mathrm{HA})$ and head inhibition $(\mathrm{HI})$ emerged from a series of transplantation experiments that were performed on hydrozoan polyps in multiple laboratories all around the world during the twentieth century (Mutz, 1930; Child, 1932; Barth, 1940; Yao, 1945; Burnett, 1961; Tardent, 1963; Webster and Wolpert, 1966; Wilby and Webster, 1970). To make the issue easier to understand and more reader friendly, a unique series of experiments is described in a simplified manner in this article. In the first series of experiments Takano and Sugiyama restricted the position of insertion to the lower body column region termed position-4, i.e. below the budding zone while the origin of the donor tissue varied from position-0 to position-4 (Fig. 1A).

The following results were observed: When the donor tissue was excised from position-4 and transplanted to the same position in the host, the tissue was absorbed into the host and neither apical (tentacles) nor basal (foot) structures formed at the transplantation site. When the donor tissue was dissected from a more apical region in the donor (position-3 to position-0), then ectopic head formation was observed with an occurrence rate that was maximal when tissue was taken from position- 0 $(100 \%)$ and progressively decreasing when tissues were taken from more basal positions (i.e. $91 \%$ from position-1, $47 \%$ from position-2, 29\% from position-3, see Fig. 1A). These results demonstrated that the capacity of tissues from the body column to form ectopic heads after transplantation distributes as a gradient along the body axis with the highest value in the upper (apical) body column and the lowest, i.e. null value, in the basal region. This capacity of tissues to form ectopic heads was named head activation (Tanako and Sugiyama, 1983; MacWilliams, 1983b).

\section{Assessment of the head inhibition (HI) levels upon lateral transplantation}

With a slight modification of the transplantation procedure, the same authors could detect and quantify another tissue property. This time, they fixed the origin of the donor tissue to position-1 (a position where the donor tissue has a high head activation level) and they varied the position of transplantation onto the host from position-1 to position-4 (Fig. 1B). They recorded the following results: when the donor tissue was transplanted to the same position in the host, i.e. position-1 no head formation occurred. But when the site of transplantation was lower (i.e. more basal), then the occurrence rate of head formation was higher (Fig. 1B). This demonstrates that the capacity of head formation by the donor tissue can be affected by the contact with the host tissue, implying that the host tissue has the capacity to inhibit ectopic head formation induced by the transplanted donor tissue. This capacity of the host tissue to inhibit head formation was named
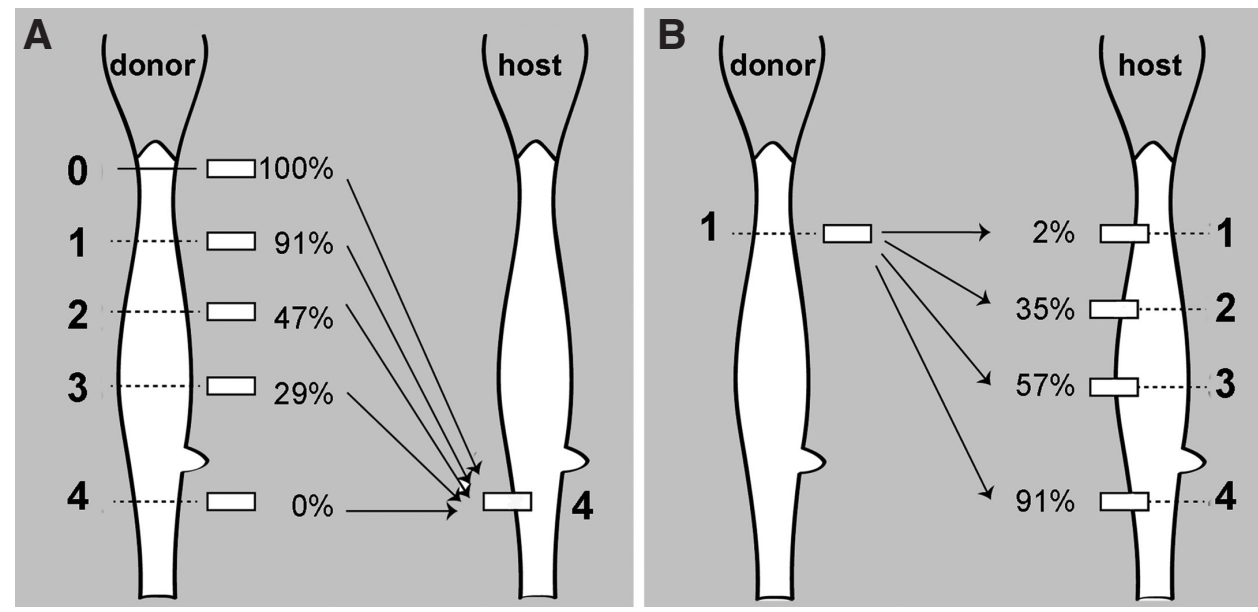

Fig. 1. Procedures to assess head activation (A) and head inhibition (B) levels upon lateral transplantation. The body column between the lower end of the tentacle ring and the first bud protrusion was optically divided into four equal lengths and the three positions thus obtained are numbered from position-1 to position-3. The body column from the lower boundary of the bud protrusion to the basal disc was optically divided into three equal lengths and the upper (apical) third was numbered position-4. (A) The donor tissue was excised as a donut ring form from position-0 to position-3 of a donor polyp, cut into a half and one of the two pieces was inserted into a slit made at position-4 in the host polyp. The polyps were observed for 5-7 days to record tentacle formation. The percentages shown

beside the donor tissues indicate the proportion of grafts that led to the formation of one or more ectopic tentacles (data from Takano and Sugiyama 1983). (B) The donor tissue was excised from position-1 and inserted into the slit made at positions 1, 2, 3 or 4 in the host polyp. The percentages beside the donor tissues indicate the proportion of host animals where ectopic tentacle formation was observed (data taken from Takano and Sugiyama, 1983). 

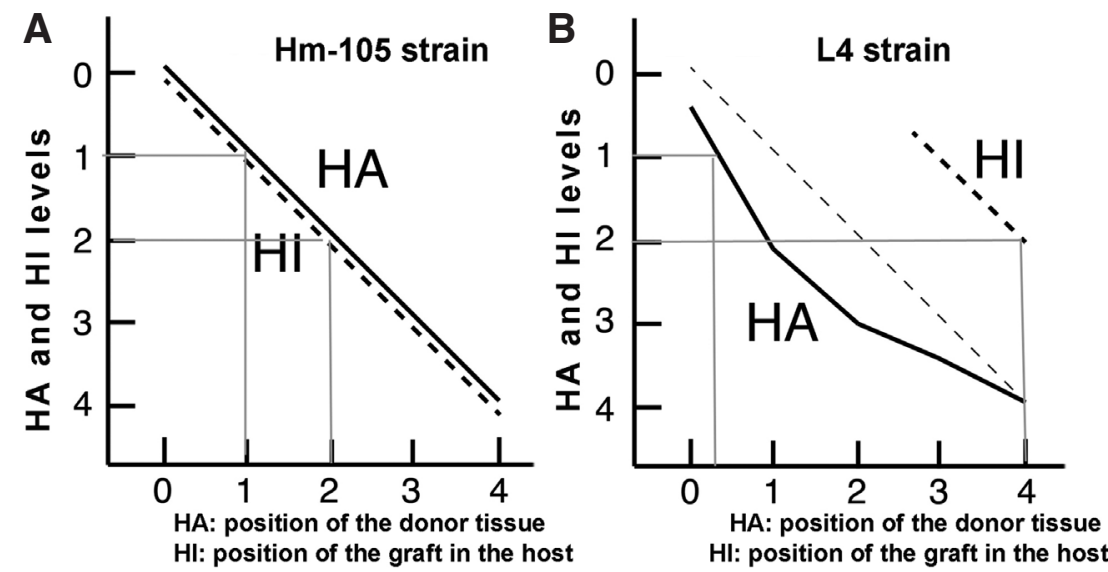

Fig. 2. Graded distribution of head activation (solid line) and head inhibition (dotted line) levels along the body column of the $\mathrm{Hm}-105$ (A) and L4 (B) strains. Head activation (HA) and head inhibition (HI) levels are deduced from the percentages of grafted animals forming ectopic heads at the site of grafting and thus correspond to inverted values: in $\mathrm{Hm}$ 105 (A), the tissues of the upper body column exhibit the highest HA (high percentage of ectopic heads with donor tissue from position-0 or position-1), but also the highest HI with low percentage of ectopic heads when tissues are grafted at position-0 or position-1 (see Fig. 1). HA and $\mathrm{HI}$ are represented here on the $\mathrm{y}$-axis by arbitrary units that can be used for comparisons between strains as indicated by the light grey lines: a HA level as high as 1 is obtained with donor tissues from a similar position in the Hm-105 and from an upper position in L4 strain (B). Meanwhile, a HI level of 2 is obtained when the graft is inserted at position 2 in Hm-105 or at position 4 in the L4 strain, showing that HI extends over a longer range along the body column of polyps of the L4 strain.

head inhibition, and again its activity distributes as a gradient along the body axis, maximal in the upper (apical) body column and progressively getting lower towards the most basal region (Tanako and Sugiyama, 1983; MacWilliams, 1983a).

In summary, head formation induced by lateral transplantation is governed by two tissue capacities that form two parallel gradients extending from the head to the foot (Fig. 2A): The first one, named head activation ( $\mathrm{HA}$ ), is the capacity of the donor tissue to form head when transplanted onto the donor and the second one, named head inhibition ( $\mathrm{HI})$ is the capacity of the host tissue to inhibit head formation (Sugiyama, 1982; Takano and Sugiyama, 1983). It should be mentioned here that the concept of inhibition in cnidarian polyps was not discovered during 1960s-1970s, but had been repeatedly proposed over the past 30 years (Barth, 1940; Rose and Rose, 1941; Penzlin, 1957; Tardent, 1955; Tardent and Eymann, 1958; Trumdell, 1958; Tardent, 1963; Lenique and Lundblad, 1966; Rose, 1966, 1967; Rose and Powers, 1966). Interestingly several authors had already indicated that this inhibition activity distributes as a gradient along the body axis of the cnidarian polyps (Hyman, 1928; Goetsch, 1929; Burt, 1934; Child, 1941; Rose, 1966).

In complementary transplantation experiments the capacity of transplants to form ectopic foot was investigated, showing that foot formation is also governed by two tissue capacities, named foot activation and foot inhibition, both of them forming parallel gradients along the body axis of Hydra but now maximal at the basal end (foot) and progressively decreasing towards the apical end (head) (Achermann and Sugiyama, 1985). However, foot formation and foot regeneration were investigated far less extensively than head formation, therefore this review is focused on head formation.

\section{Head activation (HA) and head inhibition (HI) exhibit different stabilities}

Although graded in a similar manner along the axis of the body column, the two properties significantly differ by their stability. When the head of an animal is amputated at position- 1 and the left part is allowed to regenerate, it takes about two days before the tentacle bumps become visible as a sign of head regeneration. The modulations in $\mathrm{HA}$ and $\mathrm{HI}$ activities during these two days were also examined in transplantation experiments (Fig. 3A). When the donor tissue was excised from the amputation site of the polyp 6 hours after bisection and transplanted to the host, the percentage of head formation was higher than when the transplantation takes place immediately after amputation. This result indicates that the HA level rose at the head-regenerating tip during the first 6 hours of regeneration (Fig. 3A), far before the morphological signs of head regeneration can be detected (Takano and Sugiyama, 1984). In contrast, the change of $\mathrm{HI}$ level after amputation was significantly quicker than the change of the HAlevel.

To estimate the $\mathrm{HI}$ level of the amputated host, the percentage of head formation induced by the transplant was measured on the amputated polyp rather than on the intact polyp (Fig. 3A). The percentage of head formation by the transplant taken from position-1 of an intact polyp and transferred

to position-2 of an amputated polyp was $96 \%$, a percentage significantly higher than the percentage of $30-35 \%$ recorded when the same transplant was grafted into an intact polyp. This observation strongly suggested that the $\mathrm{HI}$ level immediately dropped after amputation. Indeed complementary experiments showed that the $\mathrm{HI}$ level continues to decrease until $36 \mathrm{hr}$ and starts to increase from $48 \mathrm{hr}$ and later.

The drop of $\mathrm{HI}$ level occurs instantaneously, followed by the increase in HA level, suggesting that the two activities are mutually related. This possibility had already been supported experimentally by MacWilliams $(1983 a, b)$ who showed that when the increase in $\mathrm{HA}$ level is blocked by repeatedly removing the tissue at the regenerating tip, the recovery of $\mathrm{HI}$ level is partial suggesting that $\mathrm{HA}$ and $\mathrm{HI}$ levels regulate each other, their modulations reflecting a cross-talk between each of these two activities.

\section{Analysis of the HA and HI levels in the L4 strain}

To elucidate the mechanisms underlying the morphological properties observed in the different strains, Sugiyama and colleagues performed extensive lateral tissue transplantation experiments on the $\mathrm{mh}-1, \mathrm{~L} 4$, reg-16 strains as they exhbit interesting morphological characters (Sugiyama, 1982; Takano and Sugiyama, 1983; Achermann and Sugiyama, 1985). This procedure was possible because of the subtle tissue incompatibility between the strains collected in Japan. Although the strain mh-1 was studied first (Sugiyama, 1982), the most thorough and extensive analysis was carried out on the strain L4 (Takano and Sugiyama, 1984; Takano and Sugiyama, 1985). In this article, the results obtained in $L 4$ are first described and some additional information is then referred.

Strain L4 was collected in the lake of Hachirogata (Akita pre- 
fecture, northern Japan) as a wild-type strain. However, because of its larger polyp size and lower budding rate (when compared to strain 105) L4 was conventionally recognized as a "naturally occurring mutant". The question was then whether these morphological and developmental features were related to the $\mathrm{HA}$ and $\mathrm{HI}$ levels. A possible scenario was that a higher level of $\mathrm{HI}$ extending over a longer range might account for both characters, i.e. the larger polyp size and the lower budding rate. As to budding, it was known that the head indeed exerts an inhibitory effect on bud formation in its vicinity (Shostak, 1974; Cohen and MacWilliams, 1975). Therefore a high and long-range head inhibition would suffice to inhibit budding over a long distance, making the budding region of the animal more distant from the head, whereas even higher levels of head inhibition would definitely suppress the budding process.

The transplantation experiments showed that in L4 the HA level was slightly lower than in $\mathrm{Hm}-105$ whereas the $\mathrm{HI}$ level was significantly higher, both values supporting the scenario predicted by the authors (Fig. 2B). Concerning the stability of the $\mathrm{HA}$ and $\mathrm{HI}$ levels after head amputation, the modulations were basically the same in $\mathrm{Hm}-105$ and $\mathrm{L} 4$ with a rise in the HA level and a drop in the $\mathrm{HI}$ level, however a notable difference was the persistance of these changes over several days in L4 and not in $\mathrm{Hm}-105$ (Fig. 3B).

A similar correlation between the $\mathrm{HI}$ level and the polyp size was obtained by Rubin and Bode (1982a) working on a population named the Aberrant. This population, which appeared in the mass culture of $H$. vulgaris, showed a significantly smaller polyp size than the standard culture. Lateral transplantation experiments performed indeed showed a lower $\mathrm{HI}$ level in the Aberrant than in the normal sized polyps, suggesting a causal link. Thus the results obtained in the $L 4$ and Aberrant strains were consistent with the view that $\mathrm{HI}$ level is a key factor in the determination of the Hydra polyp size.

\section{Strategies to map the cell lineages supporting HA and HI activities}

Hydra consists of three cell lineages, ectodermal epithelial cell lineage, endodermal epithelial cell lineage, and interstitial cell (i-cell) lineage (see in this issue David, 2012; Hobmayer et al., 2012). An interesting question to ask was which of these three cell lineages is responsible for the $\mathrm{HA}$ and $\mathrm{HI}$ levels. For this analysis, the techniques developed by Marcum and Campbell (1978) and Wanek and Campbell (1982) were of tremendous importance.

\section{Construction of Ecto/Endo chimera}

The epithelial cells of Hydra constantly proliferate in the body column, however the cell number is maintained steady in homeostatic conditions. In fact cells produced in excess are gradually sloughed off from both extremities (Campbell, 1967) and when polyps undergo budding, a significant amount of cells from the parental polyp are recruited into the growing buds. This loss of cells from the polyp is made possible by the displacement of the epithelial cells along the body column (Campbell, 1967). As a result, epithelial cells do not stay at the same position in the body column but change their position constantly. Shostak et al., (1965) carried out grafting between two polyps that belong to different strains, one of them being vitally labeled in both epithelium in order to visualize the movements of the grafted tissues. Interestingly they noticed that the boundaries of the labeled ectoderm and the boundaries of the labeled endoderm did not stay adjacent to each other but with time became more distant from each other, demonstrating that the speed of the movement of the epithelial cells is not the same in the two layers.

Wanek and Campbell (1982) cleverly used this phenomenon to construct ecto/endo chimera strains. When the ectodermal and endodermal boundaries became significantly distant from each other, they excised a donut ring of tissue as such as the excised tissue consisted of the ectoderm from one strain while the endoderm was from the other strain. By allowing the tissue to regenerate, grow and proliferate, they had constructed an ecto/ endo chimera strain formed of epithelial layers from different origins (Wanek and Campbell, 1982; Wanek, 1983).

\section{Construction of nerve-free Hydra and i-cell lineage chimera}

Epithelial cells and interstitial stem cells of Hydra have different cell cycle lengths, 40 to 85 hours for the epithelial cells versus 17 to 24 hours for the interstitial stem cells (David and Campbell, 1972; Campbell and David, 1974). Campbell (1976) used colchicine, a drug that inhibits microtubule polymerization to selectively induce cell death of the fast cycling cells (see in this issue Reiter et al., 2012). Indeed a pulse treatment of several hours leads to the elimination of the interstitial stem cells while leaving the epithelial cells intact; after several days the progenies of the interstitial stem cells (nerve cells, nematocytes, gametes) are irreversibly eliminated. The polyps produced in this manner were termed "nerve-free Hydra" or "epithelial Hydra". By grafting

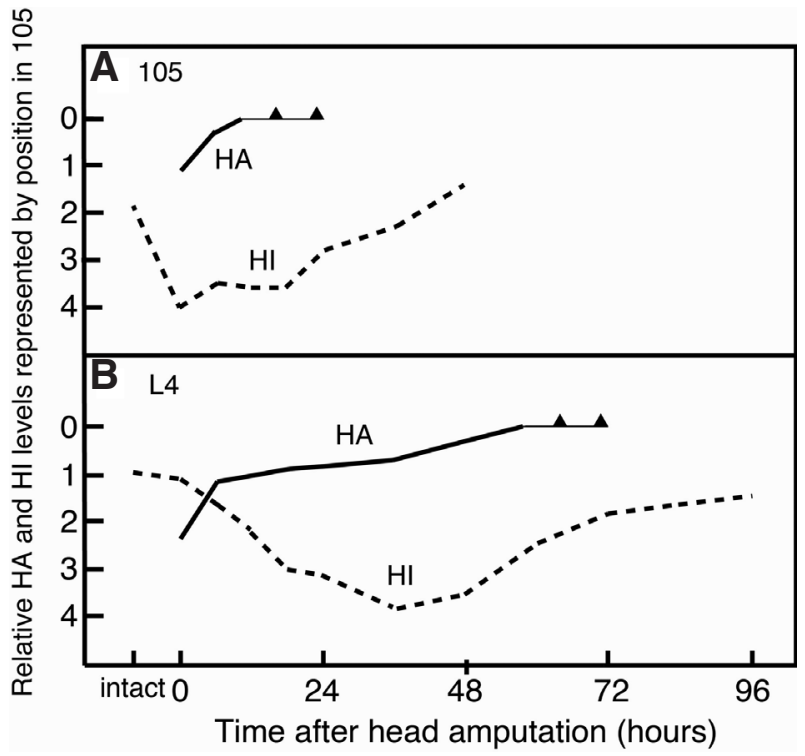

Fig. 3. Changes of head activation (solid line) and head inhibition (dotted line) levels after head removal at position-1 in the $\mathrm{Hm}-105$ (A) and L4 (B) strains. Head activation (HA) and head inhibition (HI) levels are represented with arbitrary units as specified in Fig. 2. Modified from Takano and Sugiyama (1984). Change of HA level was measured by excising donor tissues from the regenerating tip of the amputated polyps of $\mathrm{Hm}-105$ (A) and $\mathrm{L} 4$ (B) strains and grafting them into position-2 of an intact $\mathrm{Hm}-105$ polyp as the host. Change of HI level was measured by excising donor tissues from position-1 of intact polyps of $\mathrm{Hm}-105$ and by grafting them into position-2 of the amputated polyps of Hm-105 and L4 strains as the host. Arrowheads in HA and HI levels show that the level at those time points is higher than the level at position-O hence unable to evaluate. 
an intact polyp of other strains to the nerve-free polyp, Marcum and Campbell (1978) succeeded in introducing interstitial cells of a different strain into the nerve-free Hydra thereby substituting the original interstitial cell lineage and constructing i-cell lineage chimera. Finally by combining the two methods, it became possible to construct Ecto/Endo/Int chimera.

\section{Chimeric analysis in the L4 strain}

Takano and Sugiyama used the two methods mentioned above to construct Ecto/Endo/Int chimera of the $\mathrm{Hm}-105$ and L4 strains. To examine the specific effect of each cell lineage on the tissue properties and more specifically on the $\mathrm{HA}$ and $\mathrm{HI}$ levels, seven chimeric strains were constructed, namely 105/105/ L4, 105/L4/105, 105/L4/L4, L4/105/105, L4/105/L4, L4/L4/105, and $105 / 105 / 105$ (used as control instead of intact $\mathrm{Hm}-105$ ). To measure the HA levels of each type of chimera, tissue from the chimera were transplanted onto the $\mathrm{Hm}-105$, whereas donor tissue from $\mathrm{Hm}-105$ was grafted on chimeras to assess the $\mathrm{HI}$ levels (Fig. 4). In parallel the polyp size of each chimera strain was also measured to identify the cell lineage(s) responsible for the determination of this character. The results of these analyses indicated four types of conclusions: (1) in chimeras the HA level is close to that measured in the strain that provides the ectoderm, (2) in chimeras the $\mathrm{HI}$ level is close to that measured in the strain that provides the endoderm, (3) in chimeras containing the L4 i-cell lineage the $\mathrm{HI}$ level is slightly higher than in chimeras containing the $\mathrm{Hm}-105 \mathrm{i}$-cell lineage, (4) the polyp size of the chimera is close to the size of the strain that provides the endoderm.

These results suggested that (1) the ectodermal epithelial cell lineage is responsible for the HA level, (2) the endodermal epithelial lineage is responsible for the $\mathrm{HI}$ level and the polyp size, (3) the role of the i-cell lineage seems to be restricted to a moderate modulation of the HI level. Wanek and Campbell (1982) reached similar conclusions, however, they made another quite interesting observation. They constructed ecto/endo chimera

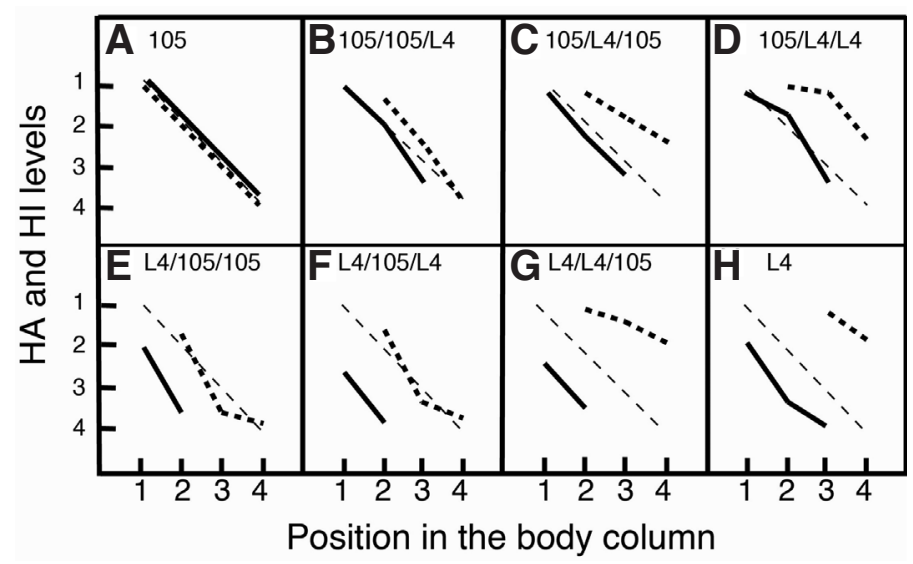

Fig. 4. Distribution of head activation (black line) and head inhibition (dotted line) levels in the chimeric strains constructed from strains Hm-105 and L4. On the x-axis, positions in the body column are defined as in Fig. 1. They indicate the position of the donor tissue for head activation (HA) level and the position in the host for head inhibition (HI) level. On the $y$-axis HA and HI levels are represented with arbitrary units as specified in Figure 2. The code is as follows: 105/105/L4 means ectoderm from Hm105 / endoderm from Hm-105 / and i-cells from L4. Modified from Takano and Sugiyama (1985). from two strains of $H$. vulgaris that exhibit a significantly different morphology of their body column. In one strain the body column was thin and tall whereas in the other strain the column was short but fat. The shape of the chimera resembled the shape of the strain that provides the ectoderm supporting the view that the ectoderm has the dominant role in shaping the body column.

However if the conclusion that the ectoderm plays the dominant role in shaping the body column was well accepted, the mechanism involved in this regulation remained unknown. In 1995 Shimizu et al., examined the orientation of the epithelial cells of the two layers at the time they divide and found that in the upper body column cells were rather dividing following a longitudinal orientation, whereas in the lower body column, which is fat, most cells were dividing following a circumferential rather than longitudinal orientation. Hence these observations showed that the pattern of epithelial cell division is region-dependent, fitting with the development of polyp shape, and suggesting that the orientation of cell division plays a role in maintaining the body column shape.

However, the question remained as to what mechanism regulates the pattern of cell division. Takaku et al., (2011) recently provided a clue to solve this problem. They found that in the elongated region of the body column where epithelial cells more likely divide along a longitudinal orientation, the microtubules in the ectodermal epithelial cells are aligned at the base of the cells following a longitudinal orientation. In contrast, this alignment was not observed in the endodermal layer. If this organization of the microtubules in the ectoderm influences the orientation of cell division by for instance, elongating the cell shape, both patterns, i.e. cell division and development of body shape, would be explained by the dynamics of the microtubules.

Another pending question was how the ectoderm and the endoderm can interact with each other while being separated by mesoglea, the extracellular matrix of Hydra. It was found that the ectodermal epithelial cells and the endodermal epithelial cells have direct contact with each other thanks to numerous protrusions that penetrate the mesoglea (Murate et al., 1997; Shimizu et al., 2008) thus enabling direct interactions between the two epithelial layers.

\section{Transplantation analyses in the head regeneration deficient reg-16 strain}

The reg-16 strain was originally obtained as a F2 progeny by crossing F1 polyps constructed by crossing wild type Hydra magnipapillata strains collected in Ugowada (Akita prefecture) that exhibit slightly lower head regenerative capacity (Sugiyama and Fujisawa, 1977b). The reg-16 strain displays a budding rate that is normal (i.e. close to that observed in $\mathrm{Hm}-105$ ) but a significantly lower head regenerative capacity. Achermann and Sugiyama (1985) examined the HA and $\mathrm{HI}$ levels in reg-16 and found as striking features a lower HA level together with a higher $\mathrm{HI}$ level when compared to those measured in $\mathrm{Hm}-105$. This $\mathrm{HA} /$ $\mathrm{HI}$ pattern in homeostatic conditions is similar to that observed in L4. However during regeneration they recorded in the reg-16 strain immediate modulations of $\mathrm{HA}$ and $\mathrm{HI}$ that are quite different from those recorded in the $\mathrm{Hm}-105$ and the L4 strains: Firstly the $\mathrm{HI}$ level did not drop after amputation, but rather remained high during 12 hours after amputation to subsequently progressively decrease; second, the rise in HA level was not prominent. These results suggested a causal link between the abnormal HA and 
$\mathrm{HI}$ properties and the reduced head regenerative capacity of the reg-16 polyps.

To examine the relationships between the cell lineages and the $\mathrm{HA}$ and $\mathrm{HI}$ levels in the reg-16 strain, Ecto/Endo/Int chimeric strains were constructed and their properties were examined by lateral tissue transplantation. Previous analyses performed on $\mathrm{Hm}-105 / \mathrm{L} 4$ chimeras had suggested that the ectoderm controls the HA level whereas the endoderm and the i-cell lineages would control the HI level (Takano and Sugiyama, 1983, 1984). The results obtained in the 105/reg-16 chimeras actually differed significantly from this scenario: the HA level was altered not only by the replacement of the ectoderm but also by the replacement of the endoderm, suggesting that both the ectoderm and the endoderm regulate the HA level in this strain. As to the HI level, the results suggested a predominant role for the endoderm in its regulation. In addition, unlike the 105/L4 chimeras, the replacement of the i-cell lineage from $\mathrm{Hm}-105$ to reg-16 origin elevated the $\mathrm{HI}$ level suggesting that the $\mathrm{i}$-cell lineage is also involved in regulating $\mathrm{HI}$ level. Interestingly Rubin and Bode (1982b) made similar observations on Hydra vulgaris strains.

The relationship between the cell lineage and the low head regenerative capacity of this strain was also examined. Replacement of the ectodermal epithelial cell lineage with Hm-105 (105/ reg-16/reg-16) elevated the percentage to a similar level in 105 (Wanek et al., 1986) whereas replacement of the endodermal epithelial cell lineage with $\mathrm{Hm}-105$ (reg-16/105/reg-16) did not elevate the percentage of regeneration. This demonstrates that the $\mathrm{Hm}-105$ ectodermal epithelial cell lineage suffices to rescue the efficiency of the regeneration process. However the number of tentacles formed was larger in the reg-16/105/reg-16 chimera than in the reg-16 strain (Nishimiya et al., 1986). These observations suggested that beside the regulation of the efficiency of the regeneration process by the ectoderm, the endoderm affects the patterning of the new head, i.e. the number of tentacles to be formed on the regenerated structure.

\section{Involvement of injury in the regeneration of reg-16 and Hm-105}

One of the drawbacks of the lateral transplantation procedure is the injury effect, i.e. the fact that lateral incisions per se activate head formation in the tissue (MacWilliams, 1982; 1983a,b). MacWilliams who found that the HA level of the transplant is elevated by the incision, proposed that this "injury effect" also works during head regeneration. Indeed this hypothesis is supported by several experimental evidences. In the reg-16 strain Kobatake and Sugiyama (1989) found that reopening the wound once healed, i.e. 24-36 hours after head amputation, elevates both the HA level and the percentage of head regeneration. This time window actually coincides with the time required for the $\mathrm{HI}$ level to drop in this strain. It is therefore possible to postulate that wound opening at the time the $\mathrm{HI}$ level drops, induces a rise in HA level. In Hm-105 independent reports relying on a different experimental approach showed the positive effect of wound opening on head formation and regeneration (Shimizu et al., 1987; Shimizu et al., 1993).

Hence as initially proposed by MacWilliams (1982, 1983a,b) the wound appears to elevate the HA level whatever the Hydra strain, and two types of mechanisms can be postulated. The first one would be direct, i.e. a direct increase of the HA level upon injury but the molecular mechanism remains unclear. The second possibility is that the leakage of the inhibitory substance(s) from the wound would trigger a rise in the $\mathrm{HA}$ level. To discriminate between these possibilities, head regeneration was performed in two distinct contexts. In one case normal head regeneration was performed in amputated polyps whereas in the other case regeneration was performed in mirror-image grafts, as such as the wound opening of two amputated polyps are immediately covered by grafting two halves to each other thanks to a nylon fishline to thread the tissues together. During the course of regeneration, the $\mathrm{HI}$ levels in the two types of regenerates did not differ significantly, whereas the HA level was higher in normal regenerates with open wound than in mirror-image grafts. This results shows that the level of HA can vary independently of the level of $\mathrm{HI}$, suggesting that injury and open wounds do not play a major role in the decrease of the $\mathrm{HI}$ level but are directly involved in the increase in the HA level.

\section{Additional questions addressed by transplantation studies}

\section{Role of nerve cells in Hydra morphogenesis}

Amphibians efficiently regenerate their appendages, either as tadpoles when frogs or as adult organisms when salamanders (Byrnes, 1904). When the nervous system of the limb is eliminated, either surgically or pharmacologically, the remaining tissue loses its regenerative capacity showing the essential role played by the nervous system in blastema proliferation (Stocum, 2004). Recent characterization of signaling molecules released by the neurons in the vicinity of the wound provides a molecular mechanism for this nerve-dependence of limb regeneration in vertebrates (Kumar et al., 2007).

In Hydra it had also been thought that head regeneration and budding require the involvement of i-cells and/or neurons (Lenz and Barnnett, 1963; Bode et al., 1973; Moore and Campbell, 1973b). Indeed both theories that describe pattern formation in Hydra, the positional information theory (Wolpert, 1969) and the theory of biological pattern formation (Gierer and Meinhardt, 1972; Meinhardt and Gierer, 1974) are based on diffusion-induced instability (Turing, 1952). Therefore nerve cells were seen as ideal candidates to regulate positional information along the body axis and set up at the site of head regeneration an environment to provoke neuron differentiation. Indeed cellular studies have proven that nerve cells accumulate in the Hydra head, providing a much higher density in the apical region than in the body column (Bode et al., 1973). The role of the nerve cells in patterning and regeneration could be tested as the i-cell lineage can be completely eliminated either by treating Hydra with drugs as Colchicine, Nitrogen mustard, Hydroxyurea (Campbell. 1976; David, 1983; Sacks and Davis, 1979) or by exposing the sf-1 strain to transient heat shock (Marcum et al., 1980). As explained above, both types of strategies produce "nerve-free" animals, i.e. Hydra that have lost their nervous system. Surprisingly the analysis of such nerve-free Hydra provided results that were entirely different from those previously predicted as Campbell showed that the nerve-free polyps retain the capacity to regenerate head and to form buds (Campbell, 1976). Moreover, Sugiyama and Wanek (1993) reported that in the head-regeneration deficient reg-16 strain, head regeneration can be rescued by the elimination of the interstitial cells (stem cells, nerve cells, nematocytes). From this 
result they discuss the possibility that in homeostatic conditions, nerve cells rather play a suppressive role on the morphogenetic potential of the epithelial cells, this negative function would be enhanced in the reg-16 mutant. These observations clearly demonstrate that head regeneration can occur independently of nerve cells in Hydra.

\section{What is the substance that is responsible for gradients along the body column?}

The morphological gradients along the body column of hydra made researchers to expect that related morphogenetic substances (morphogens) would be identified rather soon. Unfortunately, however, the substances are still yet to be discovered.

Head activator (Schaller, 1973) was proposed as a neuropeptide that is closely related to HA level and extensive analysis was performed. However, the relevance of head activator is currently questionable in that the coding sequence for it is not found in the genomic sequence of hydra (Steele, 2012). Future analysis is supposed to provide definitive information.

Currently the most probable candidate for morphogenetic substance is wnt protein. Wnt-3a is expressed at the hypostomal end of a polyp and induces secondary axis formation when ectopic expression is induced (Hobmayer et al., 2000). The wnt protein is a secreted protein which is released from the hypostome to the extracellular space. Frizzled, the receptor of wnt protein, is localized in the basal surface of epithelial cells that faces the extracellular matrix. Therefore, a possible scenario is that secreted wnt protein diffuses (see Footnote below) in the extracellular matrix from the head to the foot region forming concentration gradient and binds to Frizzled receptor thereby affecting gene expression in a position dependent manner (Meinhardt, 2012). Such a graded distribution, however, has not been found yet.

In sum, it still remains to be elucidated what kind of molecules are involved in forming and maintaining gradients of $\mathrm{HA}$ and $\mathrm{HI}$ levels.

\section{Self-organizing property of the Hydra tissues from the body column}

Here we have reported about a body of coherent information resulting from transplantation of tissue from the body column. However it is important to stress that head formation in this context does not rely on head induction but rather results from the self-organizing property of the grafted tissue. Indeed labeling experiments have shown that after grafting tissues of any region of the body column, the tissue in the ectopic head contains exclusively cells from the donor and not from the host (Broun and Bode, 2002; see also in this issue (Bode, 2012)). This is in sharp contrast to transplantation experiments as initially performed by Ethel Browne, who used tissue from the hypostome, which acts as an organizer as the grafted cells recruit cells from the host to form a secondary body axis (Browne, 1909; Mutz, 1930). In fact, the tip of the hypostome can be compared to the Spemann's organizer that induces axis formation in the Xenopus embryo and both organizers actually express a wnt-3a orthologue (Liu et

Footnote Fick's law of diffusion is not powerful enough to maintain the gradient of the wnt protein with MW of more than 30kD over the distance of 5-10 mm (Crick, 1970). Nevertheless, possibility exists that "anomalous diffusion" (Bouchaud, 1990; Havlin and Ben-Avraham, 2002) could enable formation of gradient over a long distance for such large molecules. al., 1999; Hobmayer et al., 2000). Therefore, the head inductive mechanism in Hydra has common properties to notochord inductive mechanism in frog embryos. Unfortunately, the mechanism of construction and maintenance of the graded self-organizing property along the body column of Hydra is still very poorly understood at the molecular level, although the wnt proteins are candidates as powerful morphogens.

\section{Current status of Hydra strains at the National Institute of Genetics}

After Sugiyama and Fujisawa performed their initial field collection, extensive Hydra collecting in the wild was not carried out for many years. In the late 1990s Campbell and Martinez started to collect Hydra in various parts of the world to perform phylogenetic analyses (Martinez et al., 2010). A similar phylogenetic analysis was also performed by the Japanese school (Kawaida et al., 2010) and both studies provided a similar picture of the distribution of the Hydra strains in four major species. Many of the strains collected by Sugiyama and Fujisawa are currently maintained both in California and in Japan, with approximately 220 strains available at the National Institute of Genetics, Mishima. These include strains collected in Japan, in Europe and in the US in the 1960s, 1970s, 1980s, but also strains collected by Campbell and Martinez in $21^{\text {st }}$ century, chimeric strains, and transgenic Hydra strains constructed recently in several laboratories worldwide. These strains are distributed on request to scientists for research purposes, to universities and schools for educational purposes (http://www.nig.ac.jp/labs/OntoGen/home.html).

\section{Acknowledgements}

The author wishes to thank National Institute of Genetics for financially supporting the project for preserving and maintaining hydra strains. I also wish to thank Prof. B. Galliot for her suggestions and advices in revising the manuscript.

\section{References}

ACHERMANN, J., SUGIYAMA, T. (1985). Genetic analysis of developmental mechanisms in Hydra. X. Morphogenetic potentials of a regeneration-deficient strain (reg-16). Dev Biol 107: 13-27.

BARTH, L. G. (1940). The process of regeneration in hydroids. Biol Rev 15: 405-420.

BODE, H. R., BERKING, S., DAVID, C. N., GIERER, A., SCHALLER, H., TRENKNER E. (1973). Quantitataive analysis of cell types during growth and morphogenesis in Hydra. Roux's Arch Dev Biol 171: 269-285.

BODE, H.R. (2012). The head organizer in Hydra. Int J Dev Biol 56: 473-478.

BOSSERT, P., and GALLIOT, B. (2012). How to use Hydra as a model system to teach biology in a classroom? Int J Dev Biol 56: 637-652.

BÖTTGER, A. and HASSEL, M. (2012). Hydra, a model system to trace the emergence of boundaries in eumetazoans. Int J Dev Biol 56: 583-591.

BOUCHAUD, J. (1990). Anomalous diffusion in disordered media. Physics Reports 195: 127-293

BROUN, M., BODE, H. R. (2002). Characterization of the head organizer in Hydra Development 129: 875-884.

BROWNE, E. N. (1909). The production of new Hydranths in Hydra by the insertion of small grafts. J Exp Zool 7: 1-24.

BURNETT, A. L. (1961). The growth process in Hydra. J Exp Zool 143: 21-84.

BURT, D. R. R. (1934). The capacity of different regions of Pelmato Hydra oligactis Pall. to form head or foot. J Exp Zool 68: 59-93.

BYRNES, E. F. (1904). Regeneration of the anterior limbs in the tadpoles of frogs. Roux Arch EntwMech Org 18: 171-177. 
CAMPBELL, R. D. (1967). Tissue dynamics of steady state growth in Hydra littoralis. II. Patterns of tissue movement. J. Morphol 121: 19-28.

CAMPBELL, R. D., DAVID, C. N. (1974). Cell cycle kinetics and development of Hydra attenuate. II. Interstitial cells. J Cell Sci 16: 349-358.

CAMPBELL, R. D. (1976). Elimination of Hydra interstitial and nerve cells by means of colchicine. J Cell Sci 21: 1-13.

CHILD, C.M. (1932). Determination of New Axes by Lateral Grafts and Incisions in Corymorpha in Relation to the Gradient and Dominance. Phys Zool 5: 593-627.

CHILD, C. M. (1941). Patterns and Problems of Development. Univ. of Chicago Press, Chicago.

COHEN, J. E., MACWILLIAMS, H. K. (1975). The control of foot formation in transplantation experiments in Hydra viridis. J Theor Biol 50: 87-105.

CRICK, F. H. C. (1970). Diffusion in embryogenesis. Nature 225: 420-422.

CRICK, F. H. C. (1971). The scale of pattern formation. Symp Soc Exp Biol 25: 429-438.

DAVID, C. N., CAMPBELL, R. D. (1972). Cell cycle kinetics and development of Hydra attenuata. I. Epithelial cells. J Cell Sci 11: 557-568.

DAVID, C. N. (1983). Eliminating interstitial cells with Nitrogen Mustard. pp. 299302. In Hydra: Research Methods Lenhoff, H. M. eds. Plenum Press. New York.

DAVID, C.N. (2012). Interstitial stem cells in Hydra: multipotency and decision-making. Int J Dev Biol 56: 489-497.

GIERER, A., MEINHARDT, H. (1972). A theory of biological pattern formation. Kybernetik 12: 30-39.

GOETSCH, W. (1929). Das Regenerationsmaterial und seine experimentelle Beeinflussune. Versuch zur ein heitlichen Beurteilung der Erscheinung. Roux Arch EntwMech Org 60: 127-132.

HAVLIN, S., BEN-AVRAHAM, D. (2002). Diffusion in disordered media. Adv Phys 51: 187-292.

HOBMAYER, B., RENTZSCH, F., KUHN, K., HAPPEL, C. M., VON LAUE, C. C., SNYDER, P., ROTHBÄCHER, U., HOLSTEIN, T. W. (2000). WNT signaling molecules act in axis formation in the diploblastic metazoan Hydra. Nature 407: 186-189.

HOBMAYER, B., JENEWEIN, M., EDER, D., GLASAUER, S., GUFLER, S., HARTL, M. and SALVENMOSER, W. (2012). Stemness in Hydra - a current perspective. Int J Dev Biol 56: 509-517.

HYMAN, L. (1928). Miscellaneous observations of Hydra with special reference to reproduction. Biol Bull 54: 65-108.

KAWAIDA, H., SHIMIZU, H., FUJISAWA, T., TACHIDA, H., KOBAYAKAWA, Y. (2010), Molecular phylogenetic study in genus Hydra. Gene 468: 30-40.

KOBATAKE, E., SUGIYAMA, T. (1989). Genetic analysis of developmental mechanisms in Hydra. XIX. Stimulation of regeneration by injury in the regenerationdeficient mutant strain, reg-16. Development 105: 521-528.

KUMAR, A., GODWIN, J. W., GATES, P. B., GARZA-GARCIA, A. A., BROCKES, J. P. (2007). Molecular basis for the nerve dependence of limb regeneration in an adult vertebrate. Science 318: 772-777.

LENICQUE, P. M., LUNDBLAD, M. (1966). Promoters and inhibitors of development during regeneration of the hypostome and tentacles of Hydra littoralis. Acta Zool 47: 277-288.

LENTZ, T. L., BARRNETT, R. (1963). The role of the nervous system in regenerating Hydra: the effect of neuropharmacological agents. J Exp Zool 154: 305-327.

LIU, P., WAKAMIYA, M., SHEA, M. J., ALBRECHT, U., BEHRINGER, R. R., BRADLEY, A. (1999). Requirement for Wnt3 in vertebrate axis formation. Nat Genet 22: 361-365.

LOOMIS, W. F., LENHOFF, H. M. (1956). Growth and sexual differentiation of hydra in mass culture. J Exp Zool 132: 555-574.

MACCONNELL, C. H. (1938). The hatching of Pelmatohydra oligactis eggs. Zool Anz 123: 161-174.

MACWILLIAMS, H. K. (1982). Numerical simulations of Hydra head regeneration using a proportion-regulating version of the Gierer-Meinhardt model. $J$ Theor Biol 99: 681-703.

MACWILLIAMS, H. K. (1983a). Hydra transplantation phenomena and the mechanism of Hydra head regeneration. I. Properties of the head inhibition. Dev Biol 96: $217-238$
MACWILLIAMS, H. K. (1983b). Hydra transplantation phenomena and the mechanism of Hydra head regeneration. II. Properties of the head activation. Dev Biol 96: 239-257.

MARCUM, B. A., CAMPBELL, R. D. (1978). Developmental roles of epithelial and interstitial cell lineages in Hydra: analysis of chimeras. J Cell Sci 32: 233-247.

MARCUM, B. A., FUJISAWA, T., SUGIYAMA, T. (1980). A mutant Hydra strain (sf-1) containing temperature-sensitive interstitial cells. In Development and Cellular Biology of Coelenterates (Ed.S P. Tardent and R. Tardent), pp. 429-434. Elsevier/ North-Holland, Amsterdam.

MARTINEZ, D. E., IÑIGUEZ, A. R., PERCELL, K. M., WILLNER, J. B., SIGNOROVITCH, J., CAMPBELL, R. D. (2010). Phylogeny and biogeography of Hydra (Cnidaria: Hydridae) using mitochondrial and nuclear DNA sequences. Mol Phylogenet Evol 57: 403-410.

MARTINEZ, D., BRIDGE, D. (2012). Hydra, the everlasting embryo, confronts aging. Int J Dev Biol 56: 479-487.

MEINHARDT, H., GIERER, A. (1974). Applications of a theory of biological pattern formation based on lateral inhibition. J Cell Sci 15: 321-346.

MEINHARDT, H. (2012) Modeling pattern formation in hydra: a route to understanding essential steps in development. Int. J. Dev. Biol. 56: 447-462.

MOORE, L. B., CAMPBELL, R. D. (1973a). Non-budding strains of Hydra: isolation from sexual crosses and developmental regulation of form. J Exp Zool185:73-81.

MOORE, L. B., CAMPBELL, R. D. (1973b). Bud initiation in a non-budding strain of Hydra: role of interstitial cells. J Exp Zool 184: 397-408.

MURATE, M., KISHIMOTO, Y., SUGIYAMA, T., FUJISAWA, T., TAKAHASHIIWANAGA, H., IWANAGA, T. (1997). Hydra regeneration from recombined ectodermal and endodermal tissue. II. Differential stability in the ectodermal and endodermal epithelial organization. J Cell Sci 110: 1919-1934.

MUTZ, E. (1930). Transplantationsversuche an Hydra mit besonderer bercksichtigung der induktion, regionalitt und polaritt. J Cell Sci 121: 210-271.

NISHIMIYA, C., WANEK, N., SUGIYAMA, T. (1986). Genetic analysis of developmental mechanisms in Hydra. XIV. Identification of the cell lineages responsible for the altered developmental gradients in a mutant strain, reg-16. Dev Biol115:469-478.

NISHIMAYA-FUJISAWA, C. (2012). Germline stem cells and sex determination in Hydra. Int J Dev Biol 56: 499-508.

PENZLIN, H. (1957). Experimentelle untersuchungen uiber die regeneration bei Cordylophorcaaspia Pallas. Roux Arch EntwMech Org 149: 624-643.

RAND, H. W., BOVARD, J. F., MINNICH, D. E. (1926). Location of formation agencies in Hydra. Proc Natl Acad Sci USA 12: 565-570.

REITER, S., GALLIOT, B., BUZGARIU, W. (2012). Hydra, a versatile model to study the homeostatic and developmental functions of cell death. Int $\mathrm{J}$ Dev Biol 56: 593-604.

ROSE, S. M., ROSE, R. C. (1941). The role of a cut-surface in Tubularia regeneration. Physiol Zool 14: 328-343

ROSE, S. M. (1966). Polarized inhibitory control of regional differentiation during regeneration in Tubularia. II. Separation of active materials by electrophoresis. Growth 30: 429-447.

ROSE, S. M. (1967). Polarized inhibitory control of regional differentiation during regeneration in Tubularia. III. The effects of grafts across sea water-agar bridges in electric fields. Growth 31: 149-164.

ROSE, S. M., POWERS, J. A. (1966). Polarized inhibitory control of regional differentiation during regeneration in Tubularia. I. The effect of extracts from distal and proximal regions. Growth 30: 419-427.

RUBIN, D. I., BODE, H. R. (1982a). The aberrant, a morphological mutant of Hydra attenuata, has altered inhibition properties. Dev Biol 89: 316-331.

RUBIN, D. I., BODE, H. R. (1982b). Both the epithelial cells and the nerve cells are involved in the head inhibition properties in Hydra attenuata. Dev Bio/89: 332-338.

SACKS, P. G., DAVIS L. E. (1979). Production of nerveless Hydra attenuata by hydroxyurea treatments. J Cell Sci 37: 189-203.

SCHALLER, H. C. (1973). Isolation and characterization of a low-molecular-weight substance activating head and bud formation in hydra. $J$ Embryol Exp Morphol 29: 27-38.

SHIMIZU, H., SAWADA, Y. (1987). Transplantation phenomena in Hydra: Cooperation of position-dependent and structure-dependent factors determines the transplantation result. Dev Biol 122: 113-119. 
SHIMIZU, H., SAWADA, Y., SUGIYAMA, T. (1993). Minimum tissue size required for Hydra regeneration. Dev Biol 155: 287-296.

SHIMIZU, H., SUGIYAMA, T. (1993). Suppression of head regeneration by accelerated wound healing in Hydra. Dev Biol 160: 504-511.

SHIMIZU, H., BODE, P. M., BODE, H. R. (1995). Patterns of oriented cell division during the steady-state morphogenesis of the body column in Hydra. Dev Dyn 204: 349-357.

SHIMIZU, H., AUFSCHNAITER, R., LI, L., SARRAS, M. P. Jr., BORZA, D. B., ABRAHAMSON, D. R., SADO, Y., ZHANG, X. (2008). The extracellular matrix of Hydra is a porous sheet and contains type IV collagen. Zoology 111: 410-418.

SHOSTAK, S., PATEL, N. G., BURNETT, A. L. (1965). The role of mesoglea in mass cell movement in Hydra. Dev Biol 12: 434-450.

SHOSTAK, S. (1974). Bipolar inhibitory gradients' influence on the budding region of Hydra viridis. Am Zool 14: 619-632.

SMITH, K. M., GEE, L., BLITZ, I. L., BODE, H. R. (1999). CnOtx, a member of the Otx gene family, has a role in cell movement in Hydra. Dev Biol 212: 392-404.

STEELE, R.E. (2012). The Hydra genome: insights, puzzles, and opportunities for developmental biologists. Int J Dev Biol 56: 535-542.

STOCUM, D. L. (2004). Amphibian regeneration and stem cells. Curr Top Microbiol Immunol 280: 1-70.

SUGIYAMA, T. (1982). Roles of head-activation and head-inhibition potentials in pattern formation of Hydra: Analysis of a multi-headed mutant strain. Am Zool 22: 27-34.

SUGIYAMA, T., FUJISAWA, T. (1977a). Genetic analysis of developmental mechanism in Hydra. I. Sexual reproduction of Hydra magnipapillata and isolation of mutants. Dev Growth Differ 19: 187-200.

SUGIYAMA, T., FUJISAWA, T. (1977b). Genetic analysis of developmental mechanism in Hydra. III. Characterization of a regeneration deficient strain. J Embryo Exp Morph 42: 65-77.

SUGIYAMA, T., FUJISAWA, T. (1978a). Genetic analysis of developmental mechanisms in Hydra. II. Isolation and characterization of an interstitial cell-deficient strain. J Cell Sci 29: 35-52.

SUGIYAMA, T., FUJISAWA, T. (1978b). Genetic analysis of developmental mechanisms in Hydra. IV. Characterization of a nematocyst-deficient strain. J Cell Sci 30: 175-185.

SUGIYAMA, T., FUJISAWA, T. (1979). Genetic Analysis of Developmental Mechanisms in Hydra. VII. Statistical Analyses of Developmental Morphological Characters and Cellular Compositions. Dev Growth Differ 21: 361-375.

SUGIYAMA, T., SUGIMOTO, N. (1985). Genetic analysis of developmental mechanisms in Hydra. XI. Mechanism of sex reversal by heterosexual parabiosis. Dev Biol 110: 413-421.
SUGIYAMA, T., WANEK, N. (1993). Genetic analysis of developmental mechanisms in Hydra. XXI. Enhancement of regeneration in a regeneration-deficient mutant strain by the elimination of the interstitial cell lineage. Dev Biol 160: 64-72.

TAKAKU, Y., SHIMIZU, H., FUJISAWA, T. (2011). Microtubules are involved in regulating body length in Hydra. Dev Biol 350: 228-237.

TAKANO, J., SUGIYAMA, T. (1983). Genetic analysis of developmental mechanisms in Hydra. VIII. Head-activation and head-inhibition potentials of a slow-budding strain (L4). J Embryo Exp Morph 78: 141-168.

TAKANO, J, SUGIYAMA T. (1984). Genetic analysis of developmental mechanisms in Hydra. XII. Analysis of chimaeric Hydra produced from a normal and a slowbudding strain (L4). J Embryo Exp Morph 80: 155-173.

TARDENT, P. (1955). Zum Nachweis eines regeneration schemmen den Stoffes im Hydranth von Tubularia. Rev Suisse Zool 62: 229-236.

TARDENT, P. (1963). Regeneration in the Hydrozoa. Biol Rev 38: 293-333.

TARDENT, P., EYMANN, H. (1958). Some chemical and physical properties of the regeneration inhibition of Tubularia. Acta Embryol Morphol Exp 1: 280-287.

TURING, A. M. (1952). The Chemical Basis of Morphogenesis. Phil Trans Royal Soc London B 237: 37-72.

TWEEDELL, K. S. (1958). Inhibitors of regeneration in Tubularia. Biol Bull 114: 255-269.

WANEK, N., CAMPBELL, R. D. (1982). Roles of ectodermal epithelial cells in Hydra morphogenesis: Construction of chimeric strains. J Exp Zool 221: 37-47.

WANEK, N. (1983). Roles of ectodermal and endodermal epithelial cells in Hydra morphogenesis: Analysis of chimeras. J Exp Zool 225: 89-97.

WANEK, N., NISHIMIYA, C., ACHERMANN, J., SUGIYAMA, T. (1986). Genetic analysis of developmental mechanisms in Hydra: XIII. Identification of the cell lineages responsible for the reduced regenerative capacity in a mutant strain, reg-16. Dev Biol 115: 459-468.

WEBSTER, G., WOLPERT, L. (1966). Studies on pattern regulation in Hydra. J Embryo Exp Morph 16: 91-104.

WILBY, O. K., WEBSTER, G. (1970). Experimental studies on axial polarity in Hydra. $J$ Embryo Exp Morph 24: 595-613.

WOLPERT, L. (1969). Positional information and the spatial pattern of cellular differentiation. J Theor Biol 25: 1-47.

WOLPERT, L., HICKLIN, L., HORNBRUCH, A. (1971). Positional information and pattern regulation in regeneration of Hydra. Proc Symp Soc Exp Biol25: 391-415.

WOLPERT, L., HORNBRUCH, A., CLARKE, M. R. B. (1974). Positional information and positional signaling in Hydra. Am Zool 14: 647-663.

YAO, T. (1945). Studies on the organizer problem in Pelmatohydra oligactis. I. The induction potency of the implants and the nature of the induced hydranth. $J$ Exp Biol 21: 145-150. 


\section{Further Related Reading, published previously in the Int. J. Dev. Biol.}

An organizing region in metamorphosing hydrozoan planula larvae -stimulation of axis formation in both larval and in adult tissue Melanie Stumpf, Britta Will, Karola Wittig, Jennifer Kasper, Benjamin Fischer, Jürgen Schmich, Stefanie Seipp and Thomas Leitz Int. J. Dev. Biol. (2010) 54: 795-802

Wnt signaling in hydroid development: ectopic heads and giant buds induced by GSK3beta inhibitors

Werner Müller, Uri Frank, Regina Teo, Ofer Mokady, Christina Guette and Günter Plickert

Int. J. Dev. Biol. (2007) 51: 211-220

Metamorphosis of Hydractinia echinata (Cnidaria) is caspase-dependent Stefanie Seipp, Karola Wittig, Beate Stiening, Angelika Böttger and Thomas Leitz Int. J. Dev. Biol. (2006) 50: 63-70

Patterning a multi-headed mutant in Hydractinia: enhancement of head formation and its phenotypic normalization.

Werner A Müller, Regina Teo and Frank Möhrlen

Int. J. Dev. Biol. (2004) 48: 9-15

Autoaggressive, multi-headed and other mutant phenotypes in Hydractinia echinata (Cnidaria: Hydrozoa).

Werner A Müller

Int. J. Dev. Biol. (2002) 46: 1023-1033

5 yr ISI Impact Factor $(2010)=2.961$

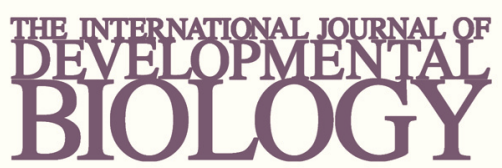

Volume 54 Nos. $6 / 7$
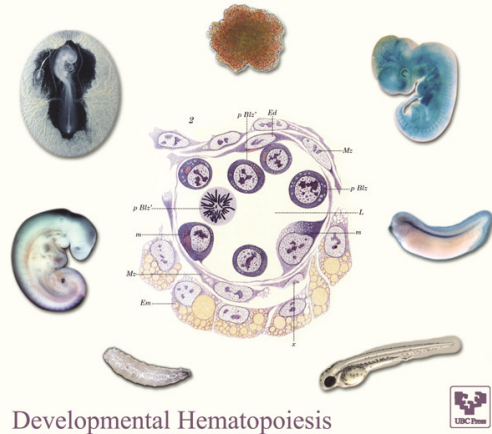

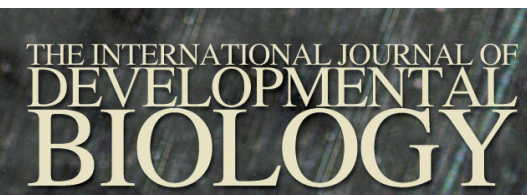

Volume 56 Nos. 1/2/3

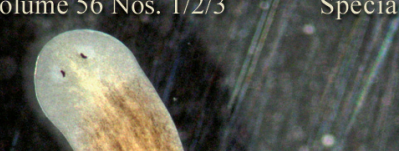

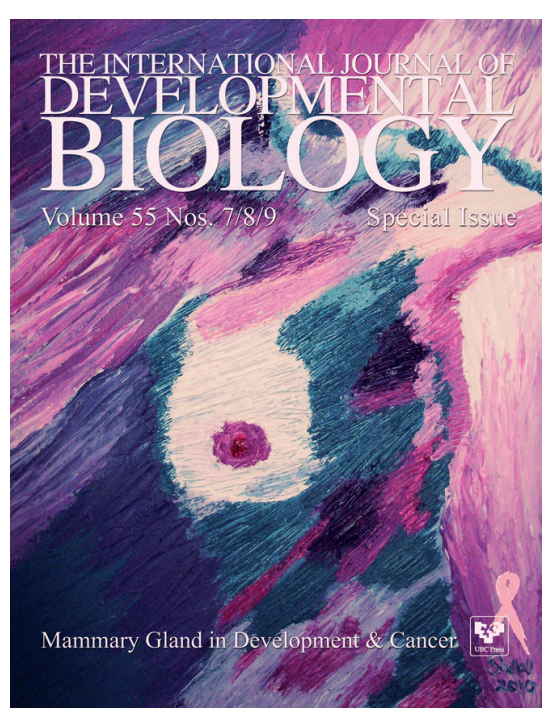

THE INTERNATIONAL JOURNAL OF
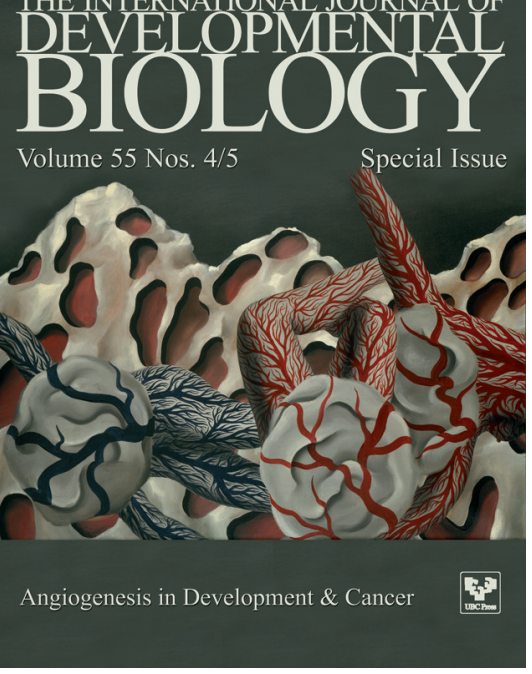